\title{
Longitudinal study to assess changes in arterial stiffness and cardiac output parameters among low- risk pregnant women
}

Mohamed Waseem Osman ${ }^{1}$, Mintu Nath², Asma Khalil ${ }^{3}$, David R Webb ${ }^{4}$, Thompson G. Robinson $^{5}$, Hatem A. Mousa ${ }^{6}$

${ }^{1}$ Clinical Research Fellow, University Hospitals of Leicester, mwo3@le.ac.uk

${ }^{2}$ Senior Biomedical Statistician, University Hospitals of Leicester, mn193@leicester.ac.uk

${ }^{3}$ Consultant/ Honorary Senior Lecturer in Maternal and Fetal Medicine, St George's University of London, akhalil@sgul.ac.uk

${ }^{4}$ Clinical Lecturer and Honorary Consultant Physician in Diabetes Medicine, Diabetes Research Centre, University of Leicester, david.webb@uhl-tr.nhs.uk

${ }^{5}$ Professor of Stroke Medicine, Department of Cardiovascular Sciences and NIHR Leicester Biomedical Research Centre, University of Leicester, tgr2@le.ac.uk

${ }^{6}$ Consultant/ Honorary Senior Lecturer in Maternal and Fetal Medicine, University of Leicester, tommy.mousa@uhl-tr.nhs.uk

Contact author address:

Dr M.W Osman

University Hospitals of Leicester

Leicester Royal Infirmary

Infirmary Close

LE1 5WW

Mwo3@le.ac.uk 
Running title: Haemodynamics among low-risk pregnant women

Number of References: 46

Number of Tables: 4

Number of Figures: 2

Keywords:

- Maternal Haemodynamics

- Arterial Stiffness

- Non-invasive cardiac output monitoring

- Pregnancy

Conflict of Interest:

The authors have no conflict of interest to declare 


\section{ABSTRACT}

\section{Aim}

A single-centre, prospective longitudinal study to assess changes in maternal arterial stiffness and cardiac output parameters among low-risk healthy pregnant women.

\section{Methodology}

Thirty low-risk, healthy, pregnant women attending their routine antenatal dating ultrasound scan were recruited. Non-invasive assessment of arterial stiffness and cardiac output was undertaken at five gestational windows from 11 to 40 weeks of pregnancy. Data were analysed using a linear mixed model incorporating time and other relevant predictors as fixed effects, and patient as a random effect.

\section{Results}

Gestational age had a significant effect on all arterial stiffness parameters, including brachial augmentation index (Alx) $(p=0.001)$, aortic $A l x(p=0.002)$ and aortic pulse wave velocity $(p=0.002)$. The aortic Alx (\%) reduced during pregnancy: the lowest mean (standard error, SE) was 4.07 (1.01) at 28 weeks before it increased to 7.04 (SE 1.64) at 40 weeks.

Similarly, non-invasive assessments of cardiac output $(p<0.001)$, stroke volume $(p=0.014)$, heart rate $(p<0.001)$ and total peripheral resistance $(p<0.001)$ demonstrated significant changes with gestational age. Mean cardiac output $(1 / \mathrm{m})$ increased during pregnancy reaching a peak at 28 weeks gestation 6.66 (SE 0.28), but dropped thereafter to reach 5.71 (SE 0.25) around term.

\section{Conclusion}

The current study provides pregnancy normograms for gestational changes in arterial stiffness and cardiac output parameters among low-risk, healthy pregnant women. Further 
work will be required to assess the risk of placental mediated diseases and pregnancy outcome among pregnant women with parameters outside the normal range. 


\section{INTRODUCTION}

Pregnancy is associated with significant cardiovascular adaptations to support the pregnancy, ensuring adequate placental perfusion and foetal development. These changes however, differ between normal and pathological pregnancies, and do precede onset of the clinical disorder ${ }^{1,2}$. Alterations in cardiac output (CO) have been associated with hypertensive diseases of pregnancy, with an increased CO being detected prior to the onset of both pre-eclampsia and gestational hypertension. ${ }^{3}$ Moreover, $\mathrm{CO}$ was noted to be reduced at the clinical manifestation of pre-eclampsia ${ }^{4}$.

Arterial stiffness is an independent predictor of cardiovascular (CV) mortality and morbidity, both in low and high risk populations ${ }^{5}$. According to the European Society of Hypertension (ESH) and European Society of Cardiology guidelines, pulse wave velocity (PWV) is a useful parameter in the stratification of $\mathrm{CV}$ risk $^{6}$. Increased systemic arterial stiffness has been reported among women with hypertensive disorders during pregnancy ${ }^{7-9}$.It is associated with foetal growth restriction ${ }^{1}$ and may have a role as a potential screening tool in pregnancy ${ }^{10}$. Scientific and clinical interest continues to grow in evaluating the role of arterial stiffness and its association with pregnancy complications and cardiovascular disorders during pregnancy ${ }^{1,9,11}$.

A number of studies ${ }^{12-18}$ have evaluated the longitudinal pattern of arterial stiffness during pregnancy; however only four studies ${ }^{13,14,16,18}$ evaluated the same group of women longitudinally through pregnancy. Three studies ${ }^{13,16,18}$ adopted applanation tonometry whilst one study ${ }^{14}$ used an oscillometric method to evaluate maternal haemodynamic parameters. The remaining studies recruited case matched controls at various gestations in pregnancy. With this modest amount of information available, it has been identified that PWV decreases mid-pregnancy ${ }^{15,17}$ and then increases non-significantly in the third trimester ${ }^{2,12,15,17}$, albeit remaining within the normal non-pregnant range. However, normal limits for PWV in pregnancy have not been reported. Recently, we have examined repeatability and diurnal variation of maternal haemodynamics amongst healthy pregnant women in their third trimester ${ }^{19}$. 
Despite the wealth of literature, there remains a lack of agreement on the longitudinal pattern of $\mathrm{CO}$ in pregnancy. $\mathrm{CO}$ was reported to follow three different patterns of change throughout pregnancy; (1) a continued increase until term ${ }^{20-22},(2)$ a steady increase, peaking in the latter half of pregnancy with a subsequent decrease to term ${ }^{23,24}$, (3) a steady increase, peaking in the latter half of pregnancy, with a plateau until term ${ }^{25-27}$.

The aim of this longitudinal study was to assess, non-invasively, changes in arterial stiffness and cardiac output parameters among low-risk healthy pregnant women in order to improve the current understanding of normal cardiac adaptation in pregnant women and to provide normograms.

\section{METHODS}

This was a prospective longitudinal study of low-risk, healthy pregnant women with a singleton viable pregnancy. Consecutive participants were invited to join the study following attendance at their routine first trimester dating ultrasound scan at the University Hospitals of Leicester NHS Trust. The study was ethically approved by Stanmore National Research Ethics Committee, Reference 12/LO/0810. Participants were excluded if they had: a BMI $>25$ at booking, multiple pregnancy, foetal anomalies, pre-pregnancy hypertension, pregnancy induced hypertension, pre-eclampsia, thyroid disease requiring medication, renal disease, liver disease, congenital or acquired cardiac condition, diabetes mellitus, were taking any medication that could affect the cardiovascular system or were current smokers.

Following informed written consent, maternal demographics were recorded.

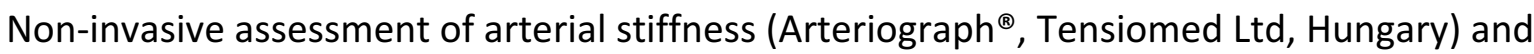
cardiac output (NICOM, Cheetah Medical, Portland, Oregon) were undertaken at five gestational windows between 11 to 40 weeks of pregnancy, in a temperature-controlled room $\left(22^{\circ} \mathrm{C}\right)$, in a semi-recumbent position. Women were examined at the following gestational windows; $11-13,20-22,26-28,32-34$ and $37-40$ weeks of pregnancy. Participants were rested for a minimum of ten minutes prior to non-invasive haemodynamic 
examination and were free from distractions, including speaking and moving, during the assessments. Participants were advised to avoid caffeine intake on the day of assessment.

Arterial stiffness measurements, PWV and augmentation index (AIx), were obtained with an Arteriograph $^{\circledR}$. This non-invasive device, used to determine arterial stiffness ${ }^{28}$, is fully automated, and has been validated against invasive and non-invasive measurements ${ }^{29,30}$, in non-pregnant populations. Despite there being no validation studies of the Arteriograph in pregnancy, the device has been used on a very large scale in pregnancy research ${ }^{29,31,32}$. The accuracy of systolic blood pressure (SBP), PWV and Alx determination has been validated against invasive monitoring ${ }^{33}$. The Arteriograph ${ }^{\circledR}$ cuff was applied to the right arm over the brachial artery for an estimation of SBP $(\mathrm{mmHg}), \mathrm{PWV}(\mathrm{m} / \mathrm{s})$ and Alx (\%) as previously described ${ }^{29}$.

The NICOM ${ }^{\circledR}$ is an operator independent device that has recently been validated against echocardiographic assessment in pregnancy and has demonstrated excellent repeatability and reproducibility, $(\text { ICC }=0.953,95 \% \mathrm{Cl} \text { 0.927-0.969, respectively })^{34}$. After initial calibration, continuous values of stroke volume (SV), CO and total peripheral resistance (TPR) were recorded; stroke volume index (SVI), cardiac Index (CI) and total peripheral resistance index (TPRI) were determined by dividing each parameter by the body surface area.

All recordings were made by one professional (MWO), who received appropriate training on use of the Arteriograph ${ }^{\circledR}$ and $\mathrm{NICOM}^{\circledR}$ devices.

\section{Statistical analysis}

We modelled the changes in each of the haemodynamic measurements, represented by Arteriograph ${ }^{\circledR}$ (brachial and aortic Alx, PWV) and $\operatorname{NICOM}^{\circledR}(\mathrm{CO}, \mathrm{Cl}, \mathrm{SV}, \mathrm{SVI}, \mathrm{HR})$ assessment, by separate linear mixed models incorporating gestational age (GA) as a fixed effect. We tested the statistical significance $(p<0.05)$ of linear, quadratic and cubic terms of $G A$ with haemodynamic measurements. The final models for brachial and aortic Alx also included heart rate, central mean arterial BP as additional fixed effects. All models included a random intercept of individual, and if statistically significant $(p<0.05)$, a random time-specific slope for each individual. All continuous variables were included in the model as a deviation from 
the population means. The final fitted model for each haemodynamic measurement was used to predict means and corresponding 95\% confidence intervals, as well as different percentiles $\left(5^{\text {th }}, 25^{\text {th }}, 50^{\text {th }}, 75^{\text {th }}, 95^{\text {th }}\right)$, across different points of GA.

All fitted models were checked for their underlying model assumptions. The model selection within a set of candidate models was assessed by comparing the log-likelihood of the nested models along with Akaike information criterion and Schwarz Bayesian information criterion. All statistical tests were two-sided with type 1 error rate ( $p$-value) of 0.05 to determine the statistical significance. All statistical analyses were carried out using the R software version 3.3 with appropriate R packages (nlme, multcomp, ggplot2) (R Core Team, 2016).

\section{RESULTS}

Thirty healthy low-risk pregnant women fulfilled the inclusion and exclusion criteria and were recruited to the study. Table 1 summarises the demographic details of our study population.

\section{Arterial Stiffness}

Significant changes in all measurements of arterial stiffness were seen during healthy pregnancy (Table 2 and Supplementary Table 1). Both brachial and aortic Alx reduced during early pregnancy, reached a nadir at 28 weeks, before increasing towards 40 weeks of gestation (Table 2, Figure 1). Both demonstrated a quadratic relationship with GA. The aortic PWV also showed a significant variation during the pregnancy: the pattern was however more complex showing a cubic relationship with GA. (Table 2, Figure 1). PWV reached its lowest value at 17 weeks of gestation and then increased, reaching a peak at 35 weeks gestation. Alx reached its lowest point at mid-pregnancy (28 weeks) and then gradually increased towards the term. Mean arterial BP and heart rate were significantly associated with measures of arterial stiffness (Table 3). Mean arterial BP demonstrated a strong positive association $(p<0.001)$ while heart rate showed a strong negative association $(p<0.001)$ with Alx. Estimated effects (standard error, SE) for mean arterial BP were 0.36 (0.05) and $0.67(0.10)$ for aortic Alx and brachial Alx, respectively, while those for heart rate were $-0.25(0.05)$ and $-0.49(0.10)$ for aortic and brachial Alx, respectively. 


\section{Cardiac output parameters}

$\mathrm{CO}$ and $\mathrm{Cl}$ demonstrated significant changes $(p<0.001)$ across GA (Table 2 , Figure 2$)$. SV also showed a significant ( $p=0.013$ ) change with GA; progressively reducing between weeks 13 and 40 of healthy pregnancy (Table 2, Figure 2, Supplementary Table 2).

Mean TPR value also changed significantly with $G A(p=0.011)$. The relationship of $G A$ with TPR was quadratic in form. Mean TPR declined initially with advancing GA reaching the lowest value around 22 weeks, and then increased at subsequent time points (Figure 2). HR also showed a significant quadratic relationship with GA ( $p<0.001)$. Mean HR values initially increased with $\mathrm{GA}$, reaching its highest value around the $30^{\text {th }}$ week, and thereafter decreased until term (Figure 2).

\section{DISCUSSION}

This study has demonstrated that normal pregnancy is associated with significant alterations in the maternal cardiovascular system, as demonstrated by the pattern of arterial stiffness and NICOM measurements, with GA having a significant effect on maternal haemodynamics. Using the linear mixed modelling framework, we were able to provide normograms for arterial stiffness and non-invasive CO parameters in healthy low-risk women, which have not been previously reported.

Our study establishes that in normal pregnancy, Alx demonstrates a gradual decline in early pregnancy, reaching its lowest value at around 28 weeks of gestation, and then increases with advancing GA to term. This is in agreement with previous reports ${ }^{13,16,35}$. The pattern of Alx in the present study suggests that maternal circulatory adaptation is completed after the first trimester and remains constant through the second trimester.

PWV demonstrated a more complex pattern, grossly resembling a sine wave. There was an initial decline to 17 weeks of gestation, increasing up to 35 weeks and subsequently declining again. This is similar to studies that have identified that PWV decreases midpregnancy $^{15,17}$ and then increases non-significantly in the third trimester ${ }^{2,12,15,17}$. However, it differs from Macedo and colleagues who observed that PWV (carotid-radial and carotid- 
femoral) did not change significantly with gestation and was marginally different between pregnant and non-pregnant women ${ }^{16}$. Normal limits for PWV in pregnancy have not been established. However, in healthy non-pregnant women the normal limit is $10 \mathrm{~m} / \mathrm{s}^{36}$. Our overall mean PWV of $7.81 \mathrm{~m} / \mathrm{s}$ is significantly lower than that expected in non-pregnant women. Several investigators proposed different mechanisms to explain the drop of PWV in the first trimester of pregnancy. It may be due to the alterations of vaso-active substances such as nitric oxide $(\mathrm{NO})^{37,38}$, progesterone, relaxin, as well as related to volume expansion in pregnancy ${ }^{13}$. The subsequent rise from the mid-trimester of pregnancy to term could be due to the inhibition of $\mathrm{NO}^{39,40}$, increase in cardiac output ${ }^{41}$ and increased circulatory volume $^{41}$.

Similarly, NICOM parameters also demonstrated a significant variation over the duration of pregnancy. It is understood that over the first two trimesters of pregnancy, CO gradually increases with the greatest increase occurring by 16 weeks of gestation ${ }^{42-44}$. The rise in CO is believed to plateau after 20 weeks of gestation but remains at that elevated level until term ${ }^{21,43}$. The increase in the heart rate and SV contribute to this increase in $\mathrm{CO}^{45}$. However, we noted that CO reached a peak at around 28 weeks of gestation and then declined to term. Changes in heart rate within our study population, mirrored previous observations by others ${ }^{45}$ and was the main influence in the pattern of $\mathrm{CO}$.

The resistance offered by the systemic circulation is either called systemic vascular resistance (SVR) or TPR. It is understood that from the $5^{\text {th }}$ week of pregnancy, there is a decline in SVR/TPR, which reaches a nadir between weeks 20 and 32 weeks $^{25,46}$. There is then a gradual increase in SVR from 32 weeks until term ${ }^{25,46}$. In this study the mean TPR declined initially with increased GA reaching the lowest value around 22 weeks, and then it increased as pregnancy advanced to term. The pattern of a reduction in SVR is due to changes in resistance and flow in multiple vascular beds, such as the utero-placental unit. These changes are necessary to allow maternal adaptation to the gravid uterus and promote the delivery of oxygen and nutrients to the foetus ${ }^{44}$.

Most studies explored maternal haemodynamics in women affected with medical conditions in pregnancy. However, in this longitudinal study, the thirty participants were required to meet stringent selection criteria to ensure that all variables such as a raised BMI, smoking or 
medical conditions ${ }^{9,16}$ (pre-eclampsia, diabetes) that may influence maternal haemodynamic parameters were eliminated. Furthermore, the women remained low risk throughout pregnancy and did not develop any medical conditions that may influence maternal haemodynamics. Arterial stiffness and NICOM measurements are usually performed in the supine position. However, in the present study, all measurements were performed in the left lateral position to avoid vena cava compression by the uterus. Therefore, the results obtained in this study are a good benchmark for normal values in pregnancy. Every effort was made to reduce selection bias in our study as women were recruited when attending a dating scan, rather than from a specific clinic. This increased the likelihood of women from a wider population being recruited. A limitation of our study is the small number of participants $(n=30)$, however, an attempt to overcome this was made with the longitudinal design of this study in which the women were investigated on five separate occasions.

The findings of this study offer a significant breakthrough in the established knowledge of maternal haemodynamics and provides a new insight into the maternal adaptation to pregnancy and may prove useful for future research as well as in clinical use.

\section{CONCLUSION}

The current study provides pregnancy normograms for gestational changes in arterial stiffness and non-invasive CO parameters among low-risk, healthy pregnant women. Further works will be required to assess the risk of placental mediated diseases and pregnancy outcome among pregnant women with parameters outside the normal pregnancy range.

\section{REFERENCES}

1. Khalil A, Sodre D, Syngelaki A, Akolekar R, Nicolaides KH. Maternal hemodynamics at 11-13 weeks of gestation in pregnancies delivering small for gestational age neonates. Fetal Diagn Ther. 
2. Khalil A, Garcia-Mandujano R, Maiz N, Elkhouli M, Nicolaides KH. Longitudinal changes in maternal hemodynamics in a population at risk for pre-eclampsia. Ultrasound Obstet Gynecol. 2014;44(2):197204. doi: 10.1002/uog.13367 [doi].

3. Bosio PM, McKenna PJ, Conroy R, O'Herlihy C. Maternal central hemodynamics in hypertensive disorders of pregnancy. Obstet Gynecol. 1999;94(6):978-984.

4. San-Frutos LM, Fernandez R, Almagro J, Barbancho C, Salazar F, Perez-Medina T. Measure of hemodynamic patterns by thoracic electrical bioimpedance in normal pregnancy and in preeclampsia. Eur J Obstet Gynecol Reprod Biol. 2005;121(2):149-153.

5. Mancia G, De Backer G, Dominiczak A, Cifkova R, Fagard R, Germano G, Grassi G, Heagerty AM, Kjeldsen SE, Laurent S, Narkiewicz K, Ruilope L, Rynkiewicz A, Schmieder RE, Struijker Boudier HA, Zanchetti A, Vahanian A, Camm J, De Caterina R, Dean V, Dickstein K, Filippatos G, Funck-Brentano C, Hellemans I, Kristensen SD, McGregor K, Sechtem U, Silber S, Tendera M, Widimsky P, Zamorano JL, Erdine S, Kiowski W, Agabiti-Rosei E, Ambrosioni E, Lindholm LH, Manolis A, Nilsson PM, Redon J, Struijker-Boudier HA, Viigimaa M, Adamopoulos S, Bertomeu V, Clement D, Farsang C, Gaita D, Lip G, Mallion JM, Manolis AJ, O’Brien E, Ponikowski P, Ruschitzka F, Tamargo J, van Zwieten P, Waeber B, Williams B,. The task force for the management of arterial hypertension of the european society of $\mathrm{H}$, the task force for the management of arterial hypertension of the european society of C. 2007 guidelines for the management of arterial hypertension: The task force for the management of arterial hypertension of the european society of hypertension (ESH) and of the european society of cardiology (ESC). Eur Heart J. 2007;28(1):462-1536.

6. Mancia G, Fagard R, Narkiewicz K, Redon J, Zanchetti A, Bo M, Christiaens M, Cifkova R, De Backer G ,Dominiczak A, Galderisi M , Grobbee D.E, Jaarsma T, Kirchhof P, Kjeldsen S.E, Laurent S, Manolis A.J, Nilsson P.M, Ruilope L.M, Schmieder R.E, Sirnes P.A, Sleight P, Viigimaa M, Waeber B, Zannad F. 
2013 ESH/ESC guidelines for the management of arterial hypertension. European Heart Journal. 2013;34:2159.

7. Tihtonen KM, Koobi T, Uotila JT. Arterial stiffness in preeclamptic and chronic hypertensive pregnancies. . Eur J Obstet Gynecol Reprod Biol. 2006;128:180.

8. Ronnback M, Lampinen K, Groop PH, Kaaja R. Pulse wave reflection in currently and previously preeclamptic women.

. Hypertens Pregnancy. 2005;24:171.

9. Hausvater A, Giannone T, Sandoval YH, et al. The association between preeclampsia and arterial stiffness. J Hypertens. 2012;30(1):17-33. doi: 10.1097/HJH.0b013e32834e4b0f [doi].

10. Osman M.W, Nath M, Breslin E.J, Khalil A, Webb D.R, Robinson T.G, Mousa H.A. Arterial stiffness measurements as a screening tool for placental mediated diseases in pregnancy: Findings of a systematic review and meta-analysis. Ultrasound in obstetrics \& gynecology : the official journal of the International Society of Ultrasound in Obstetrics and Gynecology. 2016;48(Suppl. 1):220.

11. Tomimatsu T, Fujime M, Kanayama T, et al. Maternal arterial stiffness in normotensive pregnant women who subsequently deliver babies that are small for gestational age. Eur J Obstet Gynecol Reprod Biol. 2013;169(1):24-27. doi: 10.1016/j.ejogrb.2013.01.016 [doi].

12. Pandey A.K, Siwach S, Sangwan V, Sharma S and Das A. Assessment of maternal vascular stiffness indices in three trimesters of normal pregnancy. Indian J Physiol Pharmacol. 2014;58(3):196.

13. Khalil A, Jauniaux E, Cooper D, Harrington K.K. Pulse wave analysis in normal pregnancy: A prospective longitudinal study. PloS one. 2009;4(7):6134. 
14. Franz MB, Burgmann M, Neubauer A, Zeisler H, Sanani R, Gottsauner-Wolf M, Schiessl B, Andreas M. Augmentation index and pulse wave velocity in normotensive and pre-eclamptic pregnancies. Acta Obstet Gynecol Scand. 2013;92:960.

15. Gomez Y.H, Hudda Z, Mahdi N, Hausvater A, Opatrny L, El-Messidi A, Gagnon R, Daskalopoulou S.S. Pulse pressure amplification and arterial stiffness in low-risk, uncomplicated pregnancies. Angiology. 2016;67(4):375-383.

16. Macedo M.L, Luminoso D, Savvidou M.D, McEniery C.M, Nicolaides K.H. Maternal wave reflections and arterial stiffness in normal pregnancy as assessed by applanation tonometry. Hypertension. 2008;51:1047-1051.

17. Robb A.O,Mills N.L, Din J, Smith I.B.J, Paterson F, Newby D.E, Denison F.C. Influence of the menstrual cycle, pregnancy, and preeclampsia on arterial stiffness. Hypertension. 2009;53:952-958.

18. Mahendru AA, Everett TR, Wilkinson IB, Lees CC, McEniery CM. A longitudinal study of maternal cardiovascular function from preconception to the postpartum period. J Hypertens. 2014;32(4):849856.

19. Osman M.W, Leone F, Nath M, et al. Diurnal variation and repeatability of arterial stiffness and cardiac output measurements in the third trimester of uncomplicated pregnancy. Journal of hypertension. 2017; In Press.

20. Desai DK, Moodley J, Naidoo DP. Echocardiographic assessment of cardiovascular hemodynamics in normal pregnancy. Obstet Gynecol. 2004;104:20-29.

21. Capeless EL CJ. When do cardiovascular parameters return to their preconception values? Am J Obstet Gynecol. 1991;165:883-886. 
22. Savu O, Jurcuţ R, Giuşcă S. Morphological and functional adaptation of the maternal heart during pregnancy. Circ Cardiovasc Imaging. 2012;5:289-297.

23. Mone SM, Sanders SP, Colan SD. Control mechanisms for physiological hypertrophy of pregnancy. Circulation. 1996;94:667-672.

24. Easterling TR, Benedetti TJ, Schmucker BC,. Maternal hemodynamics in normal and preeclamptic pregnancies: A longitudinal study. Obstet Gynecol. 1990;76:1061-1069.

25. Robson SC, Hunter S, Boys RJ, Dunlop W. Serial study of factors influencing changes in cardiac output during human pregnancy. Am J Physiol. 1989;256:1060-1065.

26. Ogueh $\mathrm{O}$, Brookes $\mathrm{C}$, Johnson MR. A longitudinal study of the maternal cardiovascular adaptation to spontaneous and assisted conception pregnancies. Hypertens Pregnancy. 2009;28:273-289.

27. Estensen ME, Beitnes JO, Grindheim G, et al. Altered maternal left ventricular contractility and function during normal pregnancy. Ultrasound Obstet Gynecol. 2013;41:659-666.

28. Ta^nia Pereira, Carlos Correia, Joa ̃o Cardoso. Novel methods for pulse wave velocity measurement. J. Med. Biol. Eng. 2015;35:555-565.

29. Khalil A, Akolekar R, Syngelaki A, Elkhouli M, Nicolaides KH. Maternal hemodynamics in normal pregnancies at 11-13 weeks' gestation. Fetal Diagn Ther. 2012;32:179-185.

30. Horváth IG, Németh A, Lenkey Z, Alessandri N, Tufano F, Kis P, Gaszner B, Cziráki A. Invasive validation of a new oscillometric device (arteriograph) formeasuring augmentation index, central blood pressure and aortic pulse wave velocity. J Hypertens. 2010;28:2068-2075. 
31. Khalil A, Akolekar R, Syngelaki A, Elkhouli M, Nicolaides KH. Maternal hemodynamics at 11-13 weeks' gestation and risk of pre-eclampsia. Ultrasound Obstet Gynecol. 2012;40(1):28-34. doi: 10.1002/uog.11183 [doi].

32. Asma Khalil, Rosario Garcia-Mandujano, Roxana Chiriac, Ranjit Akolekar, Kypros H. Nicolaides. Maternal hemodynamics at 11-13 weeks' gestation in gestational diabetes mellitus. Fetal Diagn Ther. 2012;31:216-220.

33. Horva'tha I.G, Nemetha A, Lenkeya Z, Alessandrib N, Tufanob F, Kisa P.I, Gasznera B and Czira' kia A. Invasive validation of a new oscillometric device (arteriograph) for measuring augmentation index, central blood pressure and aortic pulse wave velocity. Journal of Hypertension. 2010;28(000).

34. Vinayagam D, Patey $O$, Thilaganathan B, Khalil A. Non-invasive cardiac output monitoring in pregnancy: Comparison to echocardiographic assessment. Ultrasound Obstet Gynecol. 2016;Epub ahead of print.

35. Franz MB, Burgmann M, Neubauer A, et al. Augmentation index and pulse wave velocity in normotensive and pre-eclamptic pregnancies. Acta Obstet Gynecol Scand. 2013;92(8):960-966.

36. Baulmann J, Schillings U, Rickert S, Uen S, Dusing R, Illyes M, Cziraki A, Nickenig G and Mengden T. A new oscillometric method for assessment of arterial stiffness: Comparison with tonometric and piezo-electronic methods. Journal of Hypertension. 2008;26:523.

37. Delacretaz E, De Quay N, Waeber B. Differential nitric oxide synthase in human platelets during normal pregnancy and pre-eclampsia. Clin Sci (Colch). 1995;88:607-610.

38. Wilkinson IB, Qasem A, McEniery CM, Webb DJ, Avolio AP, Cockcroft JR. Nitric oxide regulates local arterial distensibility in vivo. Circulation. 2002;105:213-217. 
39. Holden DP, Fickling SA, Whitley GS, Nussey SS. Plasma concentrations of asymmetric dimethylarginine, a natural inhibitor of nitric oxide synthase, in normal pregnancy and preeclampsia. Am J Obstet Gynecol. 1998;178:551- 556.

40. McEniery CM, Wallace S, Mackenzie IS. Endothelial function is associated with pulse pressure, pulse wave velocity, and augmentation index in healthy humans. Hypertension. 2006;48:602-608.

41. Wykrêtowicz M, Krauze T, Guzik P, Piskorski J. Arterial stiffness, central hemodynamics and wave reflection in normal pregnancy and control nonpregnant women. Eur J Obstet Gynecol Reprod Biol. 2011;159(1):49-52.

42. Davey DA MM. Plasma adrenaline, noradrenaline and dopamine in pregnancy hypertension. Br J Obstet Gynaecol. 1981;88:611-618.

43. Ruys TP, Cornette J, Roos-Hesselink JW. Pregnancy and delivery in cardiac disease. J Cardiol 2013. 2013;61:107-112.

44. Clapp JF CE. Cardiovascular function before, during, and after the first and subsequent pregnancies. Am J Cardiol. 1997;80:1469-1473.

45. Hunter S RS. Adaptation of the maternal heart in pregnancy. Br Heart J. 1992;68:540.

46. Duvekot JJ, Cheriex EC, Pieters FA, Menheere PP, Peeters LH. Early pregnancy changes in hemodynamics and volume homeostasis are consecutive adjustments triggered by a primary fall in systemic vascular tone. Am J Obstet Gynecol. 1993;169:1382-1392. 


\section{FIGURE LEGENDS}

Figure 1: Relationship of gestational age with brachial augmentation index ( $\mathrm{Br} \mathrm{Alx}$ ), aortic augmentation index (Ao Alx), pulse wave velocity (PWV) and central mean arterial pressure (CMAP) measurements, based on the fitted linear mixed model. Lines represent $5^{\text {th }}, 25^{\text {th }}$, $50^{\text {th }}, 75^{\text {th }}$ and $95^{\text {th }}$ percentiles, and points represent the observed data for each patient.

Figure 2: The relationship of gestational age with cardiac output (CO), stroke volume (SV), total peripheral resistance (TPR) and Heart rate (HR) measurements, based on the fitted linear mixed model. Lines represent $5^{\text {th }}, 25^{\text {th }}, 50^{\text {th }}, 75^{\text {th }}$ and $95^{\text {th }}$ percentiles, and points represent the observed data for each patient. 
Table 1: Estimated mean (standard deviation) of different demographic variables of the study population

\begin{tabular}{|c|c|c|}
\hline Demographic characteristics & \multicolumn{2}{|c|}{ Mean (Standard deviation) } \\
\hline Maternal age, years & \multicolumn{2}{|c|}{$28.8(4.2)$} \\
\hline Body Surface Area $\left(\mathrm{m}^{2}\right)$ & \multicolumn{2}{|c|}{$1.64(0.13)$} \\
\hline Maternal height (cm) & \multicolumn{2}{|c|}{$163.2(7.4)$} \\
\hline Maternal weight (kg) & \multicolumn{2}{|c|}{$59.9(8.4)$} \\
\hline $\begin{array}{l}\text { Maternal body mass index } \\
\left(\mathrm{kg} / \mathrm{m}^{2}\right)\end{array}$ & \multicolumn{2}{|c|}{$22.1(2.6)$} \\
\hline \multirow[t]{2}{*}{ Parity } & Nulliparous & $14(47 \%)$ \\
\hline & Multiparous & $16(53 \%)$ \\
\hline \multirow[t]{3}{*}{ Ethnicity } & Caucasian & $27(90 \%)$ \\
\hline & Asian & $2(7 \%)$ \\
\hline & Middle-eastern & $1(3 \%)$ \\
\hline
\end{tabular}


Table 2: Predicted mean (95\% lower, upper confidence interval) of arterial stiffness and cardiac output measurements at five time points

$(13,20,28,34$ and 40 weeks) of gestational age (GA) obtained from the fitted linear mixed model. The table also presents the relationship of haemodynamic measurements with GA and corresponding statistical significance ( $p$-value).

\begin{tabular}{|c|c|c|c|c|c|c|c|c|c|}
\hline Gestational age & Brachial Aix & Aortic Aix & $\begin{array}{l}\text { Aortic } \\
\text { PWV }\end{array}$ & $\begin{array}{l}\text { Cardiac } \\
\text { Output }\end{array}$ & $\begin{array}{l}\text { Cardiac } \\
\text { Index }\end{array}$ & $\begin{array}{l}\text { Stroke } \\
\text { volume }\end{array}$ & $\begin{array}{c}\text { Total peripheral } \\
\text { resistance }\end{array}$ & Heart rate & $\begin{array}{c}\text { Mean } \\
\text { Arterial } \\
\text { Blood } \\
\text { Pressure }\end{array}$ \\
\hline & $\%$ & $\%$ & $\mathrm{~m} / \mathrm{s}$ & $\mathrm{I} / \mathrm{min}$ & $\mathrm{I} / \mathrm{min} / \mathrm{m}^{2}$ & $\mathrm{ml}$ & dynes.sec/cm5 & Beats/min & $\mathrm{mmHg}$ \\
\hline 13 weeks & $\begin{array}{c}-54.57 \\
(-59.92,- \\
49.21) \\
\end{array}$ & $\begin{array}{r}9.90 \\
(7.34 \\
12.46) \\
\end{array}$ & $\begin{array}{r}7.50 \\
(7.07 \\
7.92) \\
\end{array}$ & $\begin{array}{c}6.34 \\
(5.79,6.89)\end{array}$ & $\begin{array}{c}3.89 \\
(3.58,4.19)\end{array}$ & $\begin{array}{c}76.74 \\
(70.51,82.97)\end{array}$ & $\begin{array}{r}1146.57 \\
(1046.28 \\
1256.46) \\
\end{array}$ & $\begin{array}{c}83.11 \\
(78.67,87.55)\end{array}$ & $\begin{array}{r}58.27 \\
(54.65 \\
62.12) \\
\end{array}$ \\
\hline 20 weeks & $\begin{array}{c}-63.05 \\
(-66.96,- \\
59.15) \\
\end{array}$ & $\begin{array}{c}5.83 \\
(3.89,7.77)\end{array}$ & $\begin{array}{r}7.27 \\
(6.88 \\
7.66) \\
\end{array}$ & $\begin{array}{c}6.39 \\
(5.92,6.85)\end{array}$ & $\begin{array}{c}3.87 \\
(3.62,4.12)\end{array}$ & $\begin{array}{c}74.08 \\
(69.36,78.80)\end{array}$ & $\begin{array}{r}1091.08 \\
(1025.98 \\
1160.31) \\
\end{array}$ & $\begin{array}{c}90.12 \\
(86.47,93.78)\end{array}$ & $\begin{array}{c}57.65 \\
(54.32 \\
61.18) \\
\end{array}$ \\
\hline 28 weeks & $\begin{array}{c}-66.5 \\
(-70.35,- \\
62.65) \\
\end{array}$ & $\begin{array}{c}4.07 \\
(2.08,6.06)\end{array}$ & $\begin{array}{l}7.94 \\
(7.6 \\
8.28) \\
\end{array}$ & $\begin{array}{c}6.66 \\
(6.23,7.09)\end{array}$ & $\begin{array}{c}4.05 \\
(3.82,4.27)\end{array}$ & $\begin{array}{c}71.05 \\
(67.35,74.75)\end{array}$ & $\begin{array}{l}1110.75 \\
(1044.5 \\
1181.21) \\
\end{array}$ & $\begin{array}{c}93.42 \\
(89.57,97.28)\end{array}$ & $\begin{array}{c}57.39 \\
(54.36 \\
60.59) \\
\end{array}$ \\
\hline 34 weeks & $\begin{array}{c}-64.71 \\
(-68.51,- \\
60.92)\end{array}$ & $\begin{array}{c}4.76 \\
(2.95,6.58)\end{array}$ & $\begin{array}{c}8.33 \\
(7.97 \\
8.7) \\
\end{array}$ & $\begin{array}{c}6.53 \\
(6.09,6.96)\end{array}$ & $\begin{array}{c}3.98 \\
(3.75,4.21)\end{array}$ & $\begin{array}{c}68.77 \\
(64.97,72.57)\end{array}$ & $\begin{array}{c}1186.06 \\
(1120.91 \\
1255)\end{array}$ & $\begin{array}{c}92.6 \\
(88.93,96.27)\end{array}$ & $\begin{array}{c}62.85 \\
(59.37 \\
66.53)\end{array}$ \\
\hline 40 weeks & $\begin{array}{c}-59.17 \\
(-65.88,- \\
52.46) \\
\end{array}$ & $\begin{array}{c}7.19 \\
(3.99,10.4)\end{array}$ & $\begin{array}{r}8.02 \\
(7.48 \\
8.55) \\
\end{array}$ & $\begin{array}{c}5.71 \\
(5.22,6.20)\end{array}$ & $\begin{array}{c}3.48 \\
(3.21,3.75)\end{array}$ & $\begin{array}{c}66.5 \\
(61.88,71.12)\end{array}$ & $\begin{array}{r}1324.42 \\
(1233.22 \\
1422.36) \\
\end{array}$ & $\begin{array}{c}88.94 \\
(83.84,94.04)\end{array}$ & $\begin{array}{r}80.28 \\
(74.40 \\
86.62) \\
\end{array}$ \\
\hline $\begin{array}{l}\text { Relationship } \\
\text { with GA }\end{array}$ & Quadratic & Quadratic & Cubic & Cubic & Cubic & Linear & Quadratic & Quadratic & Quadratic \\
\hline p-value & 0.001 & 0.002 & 0.002 & $<0.001$ & $<0.001$ & 0.013 & 0.011 & $<0.001$ & 0.023 \\
\hline
\end{tabular}

Augmentation index (Alx), pulse wave velocity (PWV). 
Table 3: Normograms representing estimated means and standard deviations of arterial stiffness measurements, brachial augmentation index (BrAIX), aorta augmentation index (AoAIX), and pulse wave velocity (PWV), at weekly time intervals from 13 to 40 weeks of gestational age (GA).

\begin{tabular}{|c|c|c|c|c|c|c|}
\hline \multirow[b]{2}{*}{$\begin{array}{c}\text { GA } \\
\text { (weeks) }\end{array}$} & \multicolumn{2}{|c|}{ BrAIX } & \multicolumn{2}{|c|}{ AoAIX } & \multicolumn{2}{|c|}{ PWV } \\
\hline & $\begin{array}{c}\text { Mean } \\
\text { (\%) }\end{array}$ & SD & $\begin{array}{c}\text { Mean } \\
\text { (\%) }\end{array}$ & SD & $\begin{array}{l}\text { Mean } \\
(\mathrm{m} / \mathrm{s})\end{array}$ & SD \\
\hline 13 & -54.57 & 13.44 & 9.90 & 6.44 & 7.50 & 1.13 \\
\hline 14 & -56.09 & 13.24 & 9.35 & 6.44 & 7.38 & 1.13 \\
\hline 15 & -57.51 & 13.05 & 8.66 & 6.44 & 7.30 & 1.13 \\
\hline 16 & -58.83 & 12.88 & 8.02 & 6.44 & 7.25 & 1.13 \\
\hline 17 & -60.04 & 12.72 & 7.43 & 6.44 & 7.22 & 1.13 \\
\hline 18 & -61.15 & 12.57 & 6.88 & 6.44 & 7.22 & 1.13 \\
\hline 19 & -62.15 & 12.44 & 6.39 & 6.44 & 7.23 & 1.13 \\
\hline 20 & -63.05 & 12.33 & 5.94 & 6.44 & 7.27 & 1.13 \\
\hline 21 & -63.85 & 12.24 & 5.54 & 6.44 & 7.32 & 1.13 \\
\hline 22 & -64.54 & 12.16 & 5.18 & 6.44 & 7.39 & 1.13 \\
\hline 23 & -65.13 & 12.09 & 4.88 & 6.44 & 7.47 & 1.13 \\
\hline 24 & -65.61 & 12.05 & 4.62 & 6.44 & 7.56 & 1.13 \\
\hline 25 & -65.99 & 12.02 & 4.41 & 6.44 & 7.65 & 1.13 \\
\hline 26 & -66.27 & 12.01 & 4.25 & 6.44 & 7.75 & 1.13 \\
\hline 27 & -66.44 & 12.02 & 4.14 & 6.44 & 7.84 & 1.13 \\
\hline 28 & -66.50 & 12.05 & 4.08 & 6.44 & 7.94 & 1.13 \\
\hline 29 & -66.47 & 12.09 & 4.06 & 6.44 & 8.03 & 1.13 \\
\hline 30 & -66.32 & 12.16 & 4.09 & 6.44 & 8.12 & 1.13 \\
\hline 31 & -66.08 & 12.23 & 4.17 & 6.44 & 8.19 & 1.13 \\
\hline 32 & -65.73 & 12.33 & 4.30 & 6.44 & 8.25 & 1.13 \\
\hline 33 & -65.27 & 12.44 & 4.48 & 6.44 & 8.30 & 1.13 \\
\hline 34 & -64.71 & 12.57 & 4.70 & 6.44 & 8.33 & 1.13 \\
\hline 35 & -64.05 & 12.72 & 4.97 & 6.44 & 8.35 & 1.13 \\
\hline 36 & -63.28 & 12.88 & 5.29 & 6.44 & 8.34 & 1.13 \\
\hline 37 & -62.41 & 13.05 & 5.66 & 6.44 & 8.30 & 1.13 \\
\hline 38 & -61.44 & 13.24 & 6.08 & 6.44 & 8.24 & 1.13 \\
\hline 39 & -60.36 & 13.44 & 6.54 & 6.44 & 8.14 & 1.13 \\
\hline 40 & -59.17 & 13.65 & 7.06 & 6.44 & 8.02 & 1.13 \\
\hline
\end{tabular}


Table 4: Normograms representing estimated means and standard deviations of cardiac output measurements, cardiac output, stroke volume and heart rate, at weekly time interval from 13 to 40 weeks of gestational age (GA).

\begin{tabular}{|c|c|c|c|c|c|c|}
\hline & \multicolumn{2}{|c|}{ Cardiac output } & \multicolumn{2}{c|}{ Stroke volume } & \multicolumn{2}{c|}{ Heart rate } \\
\hline $\begin{array}{c}\text { GA } \\
\text { (weeks) }\end{array}$ & $\begin{array}{c}\text { Mean } \\
\text { (L/min) }\end{array}$ & SD & $\begin{array}{c}\text { Mean } \\
\text { (ml) }\end{array}$ & SD & $\begin{array}{c}\text { Mean } \\
\text { (BPM) }\end{array}$ & SD \\
\hline 13 & 6.34 & 1.51 & 76.74 & 10.49 & 83.11 & 12.36 \\
\hline 14 & 6.31 & 1.48 & 76.36 & 10.41 & 84.35 & 12.36 \\
\hline 15 & 6.30 & 1.45 & 75.98 & 10.33 & 85.51 & 12.36 \\
\hline 16 & 6.30 & 1.43 & 75.60 & 10.25 & 86.59 & 12.36 \\
\hline 17 & 6.31 & 1.40 & 75.22 & 10.17 & 87.59 & 12.36 \\
\hline 18 & 6.33 & 1.38 & 74.84 & 10.09 & 88.51 & 12.36 \\
\hline 19 & 6.35 & 1.37 & 74.46 & 10.01 & 89.36 & 12.36 \\
\hline 20 & 6.39 & 1.35 & 74.08 & 9.93 & 90.12 & 12.36 \\
\hline 21 & 6.42 & 1.34 & 73.70 & 9.84 & 90.81 & 12.36 \\
\hline 22 & 6.46 & 1.32 & 73.33 & 9.76 & 91.42 & 12.36 \\
\hline 23 & 6.50 & 1.31 & 72.95 & 9.68 & 91.95 & 12.36 \\
\hline 24 & 6.54 & 1.30 & 72.57 & 9.59 & 92.40 & 12.36 \\
\hline 25 & 6.58 & 1.29 & 72.19 & 9.50 & 92.78 & 12.36 \\
\hline 26 & 6.61 & 1.28 & 71.81 & 9.42 & 93.07 & 12.36 \\
\hline 27 & 6.64 & 1.27 & 71.43 & 9.33 & 93.29 & 12.36 \\
\hline 28 & 6.66 & 1.26 & 71.05 & 9.24 & 93.42 & 12.36 \\
\hline 29 & 6.67 & 1.25 & 70.67 & 9.15 & 93.48 & 12.36 \\
\hline 30 & 6.67 & 1.24 & 70.29 & 9.06 & 93.46 & 12.36 \\
\hline 31 & 6.66 & 1.24 & 69.91 & 8.97 & 93.36 & 12.36 \\
\hline 32 & 6.63 & 1.23 & 69.53 & 8.88 & 93.19 & 12.36 \\
\hline 33 & 6.59 & 1.22 & 69.15 & 8.78 & 92.93 & 12.36 \\
\hline 34 & 6.53 & 1.22 & 68.77 & 8.69 & 92.60 & 12.36 \\
\hline 35 & 6.45 & 1.21 & 68.39 & 8.59 & 92.18 & 12.36 \\
\hline 36 & 6.35 & 1.21 & 68.01 & 8.50 & 91.69 & 12.36 \\
\hline 37 & 6.23 & 1.20 & 67.64 & 8.40 & 91.12 & 12.36 \\
\hline 38 & 6.08 & 1.20 & 67.26 & 8.30 & 90.47 & 12.36 \\
\hline 39 & 5.91 & 1.19 & 66.88 & 8.20 & 89.75 & 12.36 \\
\hline 40 & 5.71 & 1.19 & 66.50 & 8.10 & 88.94 & 12.36 \\
\hline & & & & & & \\
\hline
\end{tabular}



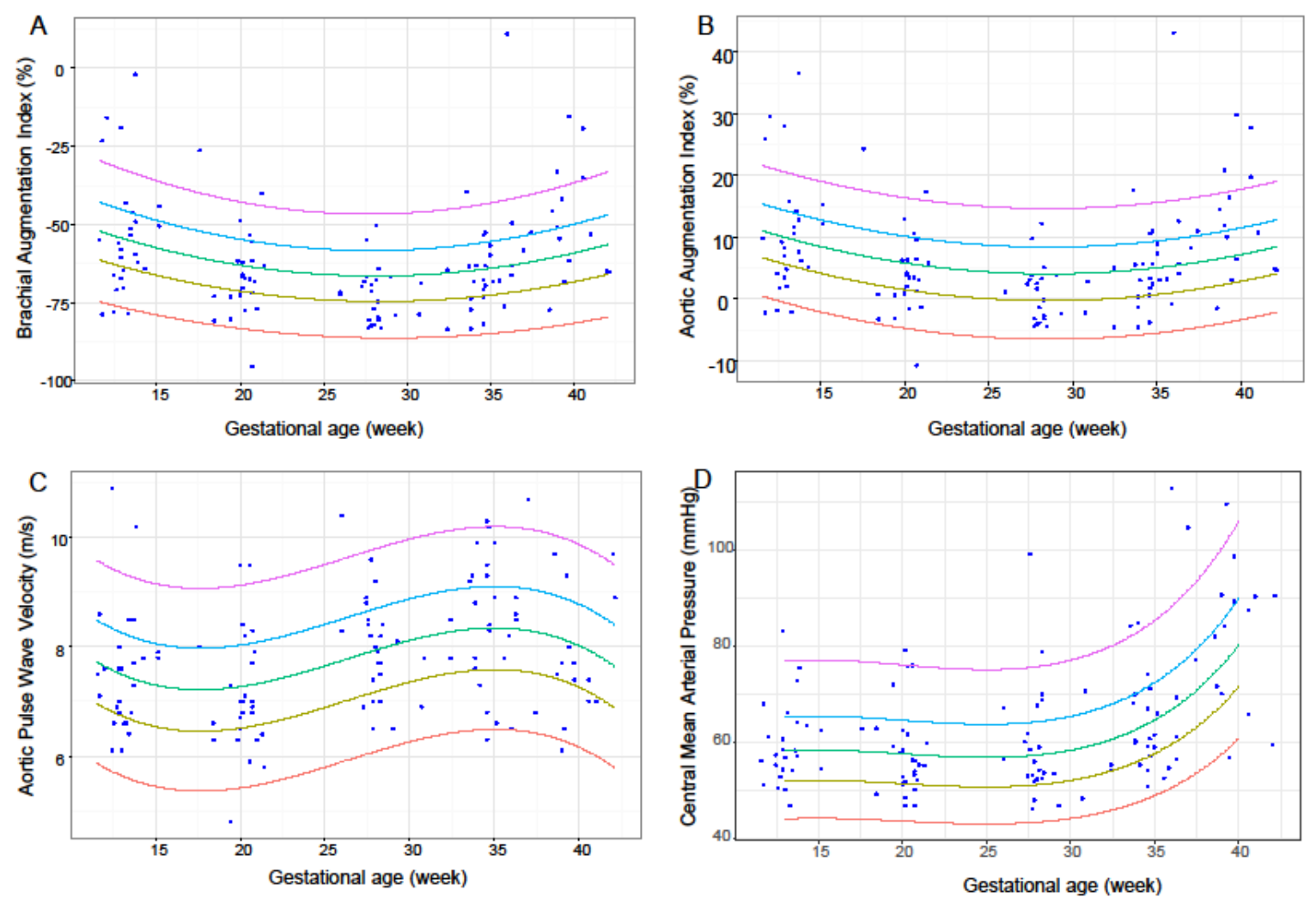

Percentile -5 th -25 th -50 th $-75_{\text {th }}-95_{\text {th }}$

Figure 1: Relationship of gestational age with brachial augmentation index ( $\mathrm{Br} \mathrm{Alx}$ ), aortic augmentation index (Ao Alx), pulse wave velocity (PWV) and central mean arterial pressure (CMAP) measurements, based on the fitted linear mixed model. Lines represent $5^{\text {th }}, 25^{\text {th }}$, $50^{\text {th }}, 75^{\text {th }}$ and $95^{\text {th }}$ percentiles, and points represent the observed data for each patient. 

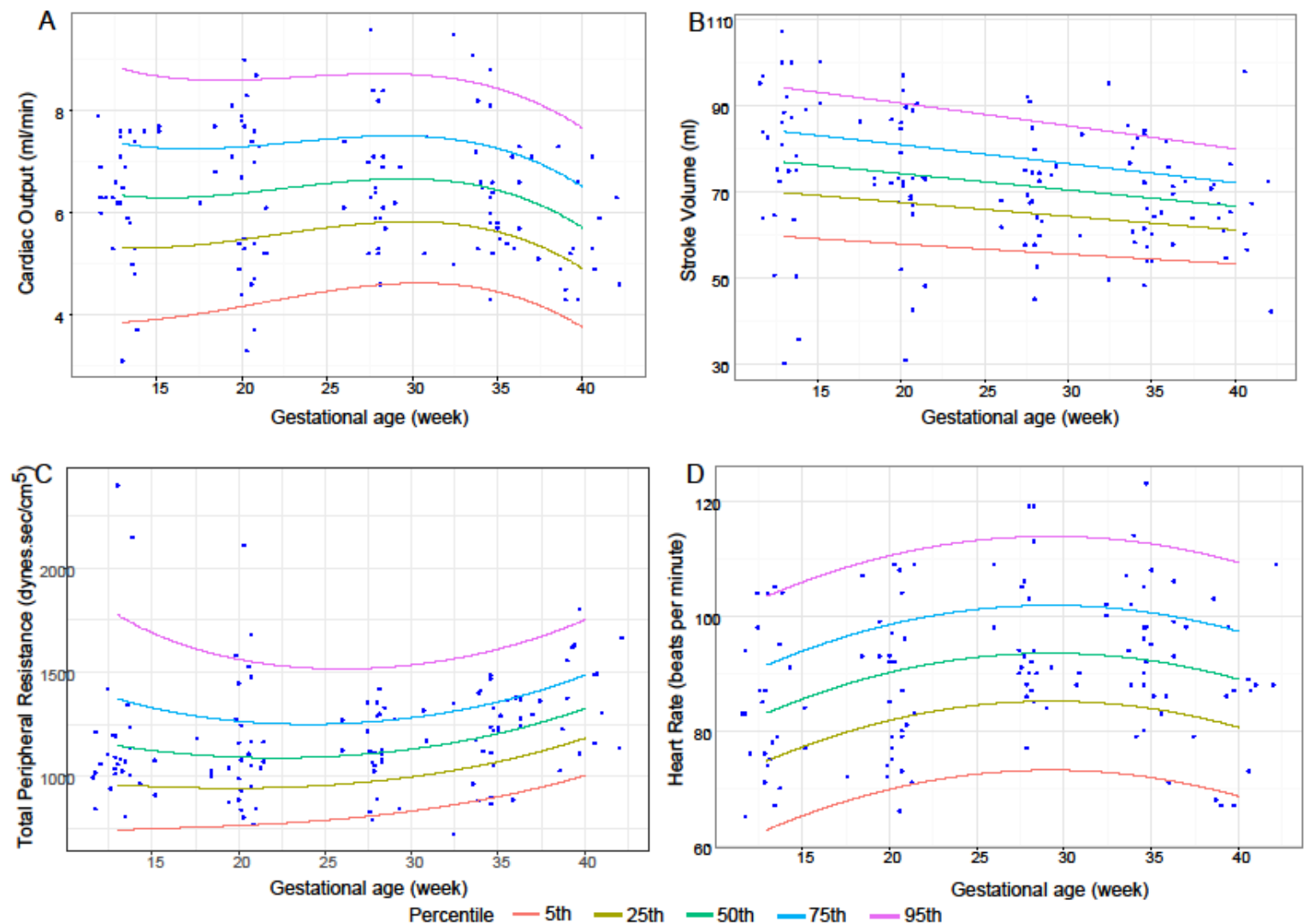

Figure 2: The relationship of gestational age with cardiac output (CO), stroke volume (SV), total peripheral resistance (TPR) and Heart rate (HR) measurements, based on the fitted linear mixed model. Lines represent $5^{\text {th }}, 25^{\text {th }}, 50^{\text {th }}, 75^{\text {th }}$ and $95^{\text {th }}$ percentiles, and points represent the observed data for each patient. 
Supplementary table 1: Estimates of mean, standard deviation and percentiles of aortic augmentation index (Ao Alx) and pulse wave velocity (PWV) at weekly time points from 13 to 40 weeks of gestation

\begin{tabular}{|c|c|c|c|c|c|c|c|c|c|c|c|c|c|c|}
\hline \multicolumn{8}{|c|}{ Ao Alx } & \multicolumn{7}{|c|}{ PWV } \\
\hline GA & Mean & SD & 5th_PC & 25th_PC & 50th_PC & 75th_PC & 95th_PC & Mean & SD & 5th_PC & 25th_PC & 50th_PC & 75th_PC & 95th_PC \\
\hline 13 & 9.90 & 6.44 & -0.69 & 5.56 & 9.90 & 14.25 & 20.50 & 7.50 & 1.13 & 5.64 & 6.73 & 7.50 & 8.26 & 9.35 \\
\hline 14 & 9.18 & 6.44 & -1.42 & 4.83 & 9.18 & 13.52 & 19.77 & 7.38 & 1.13 & 5.52 & 6.62 & 7.38 & 8.14 & 9.24 \\
\hline 15 & 8.50 & 6.44 & -2.10 & 4.15 & 8.50 & 12.84 & 19.09 & 7.30 & 1.13 & 5.44 & 6.54 & 7.30 & 8.06 & 9.16 \\
\hline 16 & 7.87 & 6.44 & -2.73 & 3.52 & 7.87 & 12.21 & 18.46 & 7.25 & 1.13 & 5.39 & 6.48 & 7.25 & 8.01 & 9.10 \\
\hline 17 & 7.29 & 6.44 & -3.31 & 2.94 & 7.29 & 11.63 & 17.88 & 7.22 & 1.13 & 5.36 & 6.46 & 7.22 & 7.98 & 9.08 \\
\hline 18 & 6.75 & 6.44 & -3.84 & 2.41 & 6.75 & 11.10 & 17.35 & 7.22 & 1.13 & 5.36 & 6.45 & 7.22 & 7.98 & 9.07 \\
\hline 19 & 6.27 & 6.44 & -4.33 & 1.92 & 6.27 & 10.61 & 16.86 & 7.23 & 1.13 & 5.38 & 6.47 & 7.23 & 8.00 & 9.09 \\
\hline 20 & 5.83 & 6.44 & -4.76 & 1.49 & 5.83 & 10.18 & 16.43 & 7.27 & 1.13 & 5.41 & 6.51 & 7.27 & 8.03 & 9.13 \\
\hline 21 & 5.44 & 6.44 & -5.15 & 1.10 & 5.44 & 9.79 & 16.04 & 7.32 & 1.13 & 5.47 & 6.56 & 7.32 & 8.09 & 9.18 \\
\hline 22 & 5.10 & 6.44 & -5.49 & 0.76 & 5.10 & 9.45 & 15.70 & 7.39 & 1.13 & 5.53 & 6.63 & 7.39 & 8.15 & 9.25 \\
\hline 23 & 4.81 & 6.44 & -5.79 & 0.47 & 4.81 & 9.15 & 15.40 & 7.47 & 1.13 & 5.61 & 6.71 & 7.47 & 8.23 & 9.33 \\
\hline 24 & 4.56 & 6.44 & -6.03 & 0.22 & 4.56 & 8.91 & 15.16 & 7.56 & 1.13 & 5.70 & 6.80 & 7.56 & 8.32 & 9.41 \\
\hline 25 & 4.37 & 6.44 & -6.23 & 0.02 & 4.37 & 8.71 & 14.96 & 7.65 & 1.13 & 5.79 & 6.89 & 7.65 & 8.41 & 9.51 \\
\hline 26 & 4.22 & 6.44 & -6.37 & -0.12 & 4.22 & 8.56 & 14.81 & 7.75 & 1.13 & 5.89 & 6.99 & 7.75 & 8.51 & 9.60 \\
\hline 27 & 4.12 & 6.44 & -6.48 & -0.22 & 4.12 & 8.46 & 14.71 & 7.84 & 1.13 & 5.99 & 7.08 & 7.84 & 8.61 & 9.70 \\
\hline 28 & 4.07 & 6.44 & -6.53 & -0.28 & 4.07 & 8.41 & 14.66 & 7.94 & 1.13 & 6.08 & 7.18 & 7.94 & 8.70 & 9.80 \\
\hline 29 & 4.06 & 6.44 & -6.53 & -0.28 & 4.06 & 8.41 & 14.66 & 8.03 & 1.13 & 6.17 & 7.27 & 8.03 & 8.79 & 9.89 \\
\hline 30 & 4.11 & 6.44 & -6.49 & -0.24 & 4.11 & 8.45 & 14.70 & 8.12 & 1.13 & 6.26 & 7.35 & 8.12 & 8.88 & 9.97 \\
\hline 31 & 4.20 & 6.44 & -6.40 & -0.15 & 4.20 & 8.54 & 14.79 & 8.19 & 1.13 & 6.33 & 7.43 & 8.19 & 8.95 & 10.05 \\
\hline 32 & 4.34 & 6.44 & -6.26 & 0.00 & 4.34 & 8.68 & 14.93 & 8.25 & 1.13 & 6.40 & 7.49 & 8.25 & 9.02 & 10.11 \\
\hline 33 & 4.53 & 6.44 & -6.07 & 0.18 & 4.53 & 8.87 & 15.12 & 8.30 & 1.13 & 6.45 & 7.54 & 8.30 & 9.06 & 10.16 \\
\hline 34 & 4.76 & 6.44 & -5.83 & 0.42 & 4.76 & 9.11 & 15.36 & 8.33 & 1.13 & 6.48 & 7.57 & 8.33 & 9.10 & 10.19 \\
\hline 35 & 5.05 & 6.44 & -5.55 & 0.70 & 5.05 & 9.39 & 15.64 & 8.35 & 1.13 & 6.49 & 7.58 & 8.35 & 9.11 & 10.20 \\
\hline 36 & 5.38 & 6.44 & -5.21 & 1.04 & 5.38 & 9.73 & 15.98 & 8.34 & 1.13 & 6.48 & 7.57 & 8.34 & 9.10 & 10.19 \\
\hline 37 & 5.76 & 6.44 & -4.83 & 1.42 & 5.76 & 10.11 & 16.36 & 8.30 & 1.13 & 6.44 & 7.54 & 8.30 & 9.06 & 10.16 \\
\hline 38 & 6.19 & 6.44 & -4.40 & 1.85 & 6.19 & 10.54 & 16.79 & 8.24 & 1.13 & 6.38 & 7.48 & 8.24 & 9.00 & 10.10 \\
\hline 39 & 6.67 & 6.44 & -3.93 & 2.32 & 6.67 & 11.01 & 17.26 & 8.14 & 1.13 & 6.29 & 7.38 & 8.14 & 8.91 & 10.00 \\
\hline 40 & 7.19 & 6.44 & -3.40 & 2.85 & 7.19 & 11.54 & 17.79 & 8.02 & 1.13 & 6.16 & 7.26 & 8.02 & 8.78 & 9.88 \\
\hline
\end{tabular}


Supplementary table 2: Estimates of mean, standard deviation and percentiles of cardiac output (CO) and stroke volume (SV) at weekly time points from 13 to 40 weeks of gestation

\begin{tabular}{|c|c|c|c|c|c|c|c|c|c|c|c|c|c|c|}
\hline \multicolumn{8}{|c|}{ Cardiac Output } & \multicolumn{7}{|c|}{ Stroke volume } \\
\hline GA & Mean & SD & 5th_PC & 25th_PC & 50th_PC & 75th_PC & 95th_PC & Mean & SD & 5th_PC & 25th_PC & 50th_PC & 75th_PC & 95th_PC \\
\hline 13 & 6.34 & 1.51 & 3.86 & 5.32 & 6.34 & 7.36 & 8.82 & 76.74 & 10.49 & 59.48 & 69.66 & 76.74 & 83.82 & 94.00 \\
\hline 14 & 6.31 & 1.48 & 3.88 & 5.32 & 6.31 & 7.31 & 8.74 & 76.36 & 10.41 & 59.23 & 69.34 & 76.36 & 83.38 & 93.49 \\
\hline 15 & 6.30 & 1.45 & 3.91 & 5.32 & 6.30 & 7.28 & 8.69 & 75.98 & 10.33 & 58.98 & 69.01 & 75.98 & 82.95 & 92.98 \\
\hline 16 & 6.30 & 1.43 & 3.95 & 5.34 & 6.30 & 7.26 & 8.64 & 75.60 & 10.25 & 58.74 & 68.69 & 75.60 & 82.52 & 92.47 \\
\hline 17 & 6.31 & 1.40 & 4.00 & 5.36 & 6.31 & 7.25 & 8.62 & 75.22 & 10.17 & 58.49 & 68.36 & 75.22 & 82.08 & 91.95 \\
\hline 18 & 6.33 & 1.38 & 4.05 & 5.39 & 6.33 & 7.26 & 8.60 & 74.84 & 10.09 & 58.24 & 68.04 & 74.84 & 81.65 & 91.44 \\
\hline 19 & 6.35 & 1.37 & 4.11 & 5.43 & 6.35 & 7.28 & 8.60 & 74.46 & 10.01 & 58.00 & 67.71 & 74.46 & 81.21 & 90.93 \\
\hline 20 & 6.39 & 1.35 & 4.17 & 5.48 & 6.39 & 7.30 & 8.61 & 74.08 & 9.93 & 57.76 & 67.39 & 74.08 & 80.78 & 90.41 \\
\hline 21 & 6.42 & 1.34 & 4.23 & 5.52 & 6.42 & 7.32 & 8.62 & 73.70 & 9.84 & 57.51 & 67.07 & 73.70 & 80.34 & 89.90 \\
\hline 22 & 6.46 & 1.32 & 4.29 & 5.57 & 6.46 & 7.35 & 8.64 & 73.33 & 9.76 & 57.27 & 66.74 & 73.33 & 79.91 & 89.38 \\
\hline 23 & 6.50 & 1.31 & 4.35 & 5.62 & 6.50 & 7.39 & 8.66 & 72.95 & 9.68 & 57.03 & 66.42 & 72.95 & 79.47 & 88.86 \\
\hline 24 & 6.54 & 1.30 & 4.41 & 5.67 & 6.54 & 7.42 & 8.68 & 72.57 & 9.59 & 56.79 & 66.10 & 72.57 & 79.03 & 88.34 \\
\hline 25 & 6.58 & 1.29 & 4.46 & 5.71 & 6.58 & 7.45 & 8.70 & 72.19 & 9.50 & 56.56 & 65.78 & 72.19 & 78.60 & 87.82 \\
\hline 26 & 6.61 & 1.28 & 4.51 & 5.75 & 6.61 & 7.47 & 8.71 & 71.81 & 9.42 & 56.32 & 65.46 & 71.81 & 78.16 & 87.30 \\
\hline 27 & 6.64 & 1.27 & 4.55 & 5.78 & 6.64 & 7.49 & 8.72 & 71.43 & 9.33 & 56.08 & 65.14 & 71.43 & 77.72 & 86.77 \\
\hline 28 & 6.66 & 1.26 & 4.59 & 5.81 & 6.66 & 7.51 & 8.73 & 71.05 & 9.24 & 55.85 & 64.82 & 71.05 & 77.28 & 86.25 \\
\hline 29 & 6.67 & 1.25 & 4.61 & 5.82 & 6.67 & 7.51 & 8.73 & 70.67 & 9.15 & 55.62 & 64.50 & 70.67 & 76.84 & 85.72 \\
\hline 30 & 6.67 & 1.24 & 4.62 & 5.83 & 6.67 & 7.51 & 8.71 & 70.29 & 9.06 & 55.39 & 64.18 & 70.29 & 76.40 & 85.19 \\
\hline 31 & 6.66 & 1.24 & 4.62 & 5.82 & 6.66 & 7.49 & 8.69 & 69.91 & 8.97 & 55.16 & 63.86 & 69.91 & 75.96 & 84.66 \\
\hline 32 & 6.63 & 1.23 & 4.61 & 5.80 & 6.63 & 7.46 & 8.65 & 69.53 & 8.88 & 54.93 & 63.54 & 69.53 & 75.52 & 84.13 \\
\hline 33 & 6.59 & 1.22 & 4.57 & 5.76 & 6.59 & 7.41 & 8.60 & 69.15 & 8.78 & 54.70 & 63.23 & 69.15 & 75.08 & 83.60 \\
\hline 34 & 6.53 & 1.22 & 4.52 & 5.71 & 6.53 & 7.35 & 8.53 & 68.77 & 8.69 & 54.48 & 62.91 & 68.77 & 74.63 & 83.07 \\
\hline 35 & 6.45 & 1.21 & 4.45 & 5.63 & 6.45 & 7.27 & 8.44 & 68.39 & 8.59 & 54.26 & 62.60 & 68.39 & 74.19 & 82.53 \\
\hline 36 & 6.35 & 1.21 & 4.36 & 5.53 & 6.35 & 7.16 & 8.33 & 68.01 & 8.50 & 54.04 & 62.28 & 68.01 & 73.75 & 81.99 \\
\hline 37 & 6.23 & 1.20 & 4.25 & 5.41 & 6.23 & 7.04 & 8.20 & 67.64 & 8.40 & 53.82 & 61.97 & 67.64 & 73.30 & 81.45 \\
\hline 38 & 6.08 & 1.20 & 4.11 & 5.27 & 6.08 & 6.89 & 8.05 & 67.26 & 8.30 & 53.60 & 61.66 & 67.26 & 72.86 & 80.91 \\
\hline 39 & 5.91 & 1.19 & 3.95 & 5.10 & 5.91 & 6.71 & 7.87 & 66.88 & 8.20 & 53.38 & 61.34 & 66.88 & 72.41 & 80.37 \\
\hline 40 & 5.71 & 1.19 & 3.75 & 4.91 & 5.71 & 6.51 & 7.66 & 66.50 & 8.10 & 53.17 & 61.03 & 66.50 & 71.96 & 79.82 \\
\hline
\end{tabular}


